\title{
Association between Serum Bilirubin and Estimated Glomerular Filtration Rate among Elderly Persons
}

\author{
Ryuichi Kawamoto ${ }^{1,2 *}$, Daisuke Ninomiya ${ }^{1,2}$, Yoichi Hasegawa ${ }^{1,2}$, \\ Yoshihisa Kasai $^{2}$, Tomo Kusunoki ${ }^{2}$, Nobuyuki Ohtsuka ${ }^{2}$, Teru Kumagi ${ }^{1}$ \\ 1. Department of Community Medicine, Ehime University Graduate School of Medicine, Ehime, Japan, 2. \\ Department of Internal Medicine, Seiyo Municipal Nomura Hospital, Ehime, Japan \\ *rykawamo@m.ehime.ca.jp
}

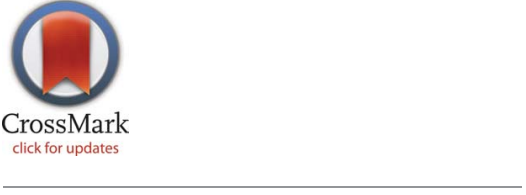

OPEN ACCESS

Citation: Kawamoto R, Ninomiya D, Hasegawa Y, Kasai Y, Kusunoki T, et al. (2014) Association between Serum Bilirubin and Estimated Glomerular Filtration Rate among Elderly Persons. PLoS ONE 9(12): e115294. doi:10.1371/journal.pone. 0115294

Editor: Valquiria Bueno, UNIFESP Federal University of São Paulo, Brazil

Received: July 24, 2014

Accepted: November 21, 2014

Published: December 16, 2014

Copyright: (c) 2014 Kawamoto et al. This is an open-access article distributed under the terms of the Creative Commons Attribution License, which permits unrestricted use, distribution, and reproduction in any medium, provided the original author and source are credited.

Data Availability: The authors confirm that all data underlying the findings are fully available withou restriction. All relevant data are within the paper.

Funding: This study was supported, in part, by a grant-in-aid from the Foundation for the Development of the Community (2014). No additional external funding received for this study. The funders had no role in study design, data collection and analysis, decision to publish, or preparation of the manuscript.

Competing Interests: The authors have declared that no competing interests exist.

\section{Abstract}

Chronic kidney disease (CKD) is a major public health problem. However, few studies have examined the significance of serum bilirubin as a risk factor for the development of CKD in the general Japanese population. The subjects comprised 413 men (mean age: $79 \pm 9$ years; (range, 60-100 years) and 637 women (mean age: $81 \pm 8$ years; range, 60-106 years) who visited the medical department of Seiyo Municipal Nomura Hospital. We examined the relationship between increased serum bilirubin and renal function that was evaluated by estimated glomerular filtration rate (eGFR) using CKD-EPI equations modified by a Japanese coefficient. Stepwise multiple regression analysis with eGFR as the objective variable, and adjusted risk factors as the explanatory variables, showed that serum bilirubin ( $\beta=0.11, P<0.001$ ) was significantly and independently associated with eGFR, in addition to gender, age, prevalence of antihypertensive medication, triglycerides, prevalence of antidiabetic medication, and serum uric acid. Compared with stages $1+2$ (eGFR $\geq 60.0 \mathrm{ml} / \mathrm{min} / 1.73 \mathrm{~m}^{2}$ ), mean multivariate-adjusted odds ratio $\{95 \%$ (confidence interval $(\mathrm{Cl})\}$ for hypobilirubinemia (first quartile, $<0.52 \mathrm{mg} /$ $\mathrm{dL}$ ) was 3.52 (range: 1.88-6.59). Next, to control potential confounding factors, data were further stratified by gender, age, medication (antihypertensive, antidyslipidemic, and antidiabetic agents), and prevalence of cardiovascular disease. The standardized coefficient for eGFR was significant in both groups, and there was no interaction between the groups. Our data demonstrated an independent positive association between serum bilirubin and eGFR in both genders. Low serum bilirubin level would be useful as a potential risk factor for renal function. 


\section{Introduction}

The increasing prevalence of chronic kidney disease (CKD) is a major public health problem [1]. There is now convincing evidence that CKD can be detected using simple laboratory tests and is associated with high annual rates of cardiovascular complications and all-cause mortality [2, 3, 4$]$. Identifying additional risk factors for CKD other than known risk factors such as reduced estimated glomerular filtration rate (eGFR) and increased urinary excretion of microalbumin may be helpful to predict future renal failure in CKD patients and prevent progression of the disease to renal failure.

Serum bilirubin, a major intravascular product of heme catabolism, has welldocumented neurotoxic effects in infants [5] , however, current evidences demonstrate that mildly elevated serum bilirubin is a potent antioxidant that may provide important protection against inflammation, cardiovascular disease (CVD), and all-cause mortality in adults [6, 7] . Several large studies have shown a positive relationship between serum bilirubin and eGFR [8. 9, 10,11], indicating that serum bilirubin has a potential renoprotective effect. However, Targher et al. found that serum bilirubin was negatively associated with eGFR, suggesting that serum bilirubin is a renal risk factor [12].

We have evaluated the relationship between serum bilirubin and potential risk factors such as hypertension, hyperglycemia, and lipids, as well as renal function, using cross-sectional data from elderly persons.

\section{Materials and Methods}

\section{Subjects}

Subjects for this investigation were recruited from among consecutive patients aged $\geq 60$ years that visited the medical department of Seiyo Municipal Nomura Hospital. Participants with severe cardio-renal or nutritional disorders that would affect BP, lipid and glucose metabolisms were excluded. Thus, 1,050 elderly persons were enrolled in the study. All procedures were approved by the Ethics Committee of Seiyo Municipal Nomura Hospital, and written informed consent was obtained from each subject.

\section{Evaluation of Confounding Factors}

Information on demographic characteristics and confounding factors was collected using the clinical files of the patients. Body mass index (BMI) was calculated by dividing weight (in kilograms) by the square of the height (in meters). We measured systolic blood pressure (SBP) and diastolic blood pressure (DBP) in the right upper arm of patients while in a sedentary position using a standard sphygmomanometer or an automatic oscillometric blood pressure recorder. Smoking status was defined as the number of cigarette packs per day multiplied by the number of years smoked (pack year) irrespective of the difference between current and past smoking status: never, light ( $<20$ pack year), 
moderate (20-39 pack year), and heavy ( $\geq 40$ pack year). Fasting total cholesterol (T-C), TG, high-density lipoprotein cholesterol (HDL-C), fasting plasma glucose (FPG), creatinine (enzymatic method), uric acid, and serum bilirubin were measured within 24 hours after admission. Low-density lipoprotein cholesterol (LDL-C) level was calculated by the Friedewald formula [13]. Patients with TG levels of $\geq 400 \mathrm{mg} / \mathrm{dL}$ were excluded. eGFR was calculated using CKD-EPI equations modified by a Japanese coefficient (eGFR $\mathrm{CKDEPI})$ : Male, $\mathrm{Cr} \leq 0.9 \mathrm{mg} / \mathrm{dl}$, $141 \times(\mathrm{Cr} / 0.9)^{-0.411} \times 0.993^{\text {age }} \times 0.813 ; \mathrm{Cr}>0.9 \mathrm{mg} / \mathrm{dl}, 141 \times(\mathrm{Cr} / 0.9)^{-1.209}$ $\times 0.993^{\text {age }} \times 0.813$; Female, $\mathrm{Cr} \leq 0.7 \mathrm{mg} / \mathrm{dl}, 144 \times(\mathrm{Cr} / 0.7)^{-0.329} \times 0.993^{\text {age }}$ $\times 0.813 ; \mathrm{Cr}>0.7 \mathrm{mg} / \mathrm{dl}, 144 \times(\mathrm{Cr} / 0.7)^{-1.209} \times 0.993^{\text {age }} \times 0.813$ [14]. Histories of antihypertensive, antidyslipidemic, and antidiabetic medication use were also evaluated. Moreover, ischemic stroke, ischemic heart disease, and peripheral vascular disease were defined as CVD.

\section{Statistical analysis}

All values are expressed as the mean \pm standard deviation (SD), unless otherwise specified, and in the cases of parameters with non-normal distribution (such as TG, FPG, and serum bilirubin), the data are shown as median (interquartile range) values. In all the analyses, parameters with non-normal distributions were used after log-transformation. Statistical analysis was performed using IBM SPSS Statistics Version 21 (Statistical Package for Social Science Japan, Inc., Tokyo, Japan). Differences in means and prevalence among the groups were analyzed by Student's t-test for continuous data and $\chi^{2}$ test for categorical data, respectively. Pearson's correlations were calculated in order to characterize the associations between various characteristics and eGFR. Multiple linear regression analysis was used to evaluate the contribution of each confounding factor to eGFR. Subjects were divided into four groups based on stage of eGFR (stage 1, eGFR $\geq 90$; stages 2, eGFR $\geq 60$; stage $3 a, 60.0$ to 45.0 ; stage $3 \mathrm{~b}, 44.9$ to 30.0 ; stage $4,<30 \mathrm{~mL} / \mathrm{min} /$ $1.73 \mathrm{~m}^{2}$ ) and quartile of serum bilirubin (Quartile-1, 0.21-0.51; Quartile-2, 0.520.71; Quartile-3, 0.72-0.99; Quartile-4, 1.00-2.00 mg/dL), and logistic regression analyses were used to test significant determinants of CKD serving as the dichotomous outcome variable. To examine the consistency of the observed association between serum bilirubin levels and eGFR, we performed subgroup analyses by age ( $<80, \geq 80$ years), medication (such as antihypertensive, antidyslipidemic, and antidiabetic agents) (absent, present), and CVD (absent, present). Interaction between serum bilirubin and the subgroups was analyzed by a general linear model. A value of $\mathrm{p}<0.05$ was considered significant.

\section{Results}

Subject background factors categorized by serum bilirubin level Table 1 shows the value of each background factor categorized by serum bilirubin level. The subjects comprised 413 men aged $79 \pm 9$ (range, 60-100) years and 637 
Table 1. Characteristics of various risk factors of the subjects by estimated glomerular filtration ratio.

\begin{tabular}{|c|c|c|c|c|c|}
\hline CKD group (mL/min/1.73 $\left.\mathrm{m}^{2}\right)$ & Stages $1+2$ & Stage $3 a$ & Stage $3 b$ & Stage 4 & \\
\hline eGFR by CKD-EPI equation & $\geq 60.0$ & $59.9-45.0$ & $44.9-30.0$ & $30.0>$ & $P$ for trend $^{*}$ \\
\hline Characteristic $N=1,050$ & $\mathbf{N}=554$ & $\mathbf{N}=228$ & $\mathbf{N}=154$ & $\mathrm{~N}=114$ & \\
\hline Gender male, (\%) & 41.0 & 41.2 & 36.4 & 31.6 & 0.220 \\
\hline Age (years) & $79 \pm 8$ & $82 \pm 8$ & $85 \pm 7$ & $84 \pm 8$ & $<0.001$ \\
\hline Body mass index $\uparrow\left(\mathrm{kg} / \mathrm{m}^{2}\right)$ & $21.1 \pm 3.7$ & $21.9 \pm 4.0$ & $21.6 \pm 4.1$ & $21.6 \pm 4.4$ & 0.060 \\
\hline Smoking status: $(\%)$ & $75.1 / 3.6 / 9.2 / 12.1$ & $80.7 / 2.2 / 7.0 / 10.1$ & 78.6/1.3/7.8/12.3 & $80.7 / 2.6 / 5.3 / 11.4$ & 0.676 \\
\hline Systolic blood pressure $(\mathrm{mmHg})$ & $137 \pm 25$ & $138 \pm 24$ & $134 \pm 25$ & $131 \pm 31$ & 0.087 \\
\hline Diastolic blood pressure $(\mathrm{mmHg})$ & $76 \pm 14$ & $77 \pm 14$ & $73 \pm 15$ & $69 \pm 14$ & $<0.001$ \\
\hline Antihypertensive medication (\%) & 48.0 & 57.0 & 68.2 & 67.5 & $<0.001$ \\
\hline Triglycerides (mg/dL) & $73(57-102)$ & $81(62-109)$ & $82(64-116)$ & $101(68-139)$ & $<0.001$ \\
\hline HDL cholesterol (mg/dL) & $56 \pm 17$ & $56 \pm 17$ & $53 \pm 18$ & $51 \pm 19$ & 0.013 \\
\hline LDL cholesterol (mg/dL) & $106 \pm 38$ & $105 \pm 34$ & $99 \pm 36$ & $98 \pm 36$ & 0.048 \\
\hline Antidyslipidemic medication (\%) & 7.9 & 10.1 & 5.2 & 9.6 & 0.348 \\
\hline Fasting blood glucose $(\mathrm{mg} / \mathrm{dL})$ & $115(99-147)$ & $119(98-145)$ & $122(100-157)$ & $126(104-148)$ & 0.217 \\
\hline Antidiabetic medication (\%) & 19.9 & 17.1 & 18.2 & 31.6 & 0.012 \\
\hline Serum uric acid (mg/dL) & $4.6 \pm 1.5$ & $5.5 \pm 1.5$ & $6.6 \pm 1.9$ & $8.0 \pm 2.5$ & $<0.001$ \\
\hline Serum creatinine $(\mathrm{mg} / \mathrm{dL})$ & $0.67 \pm 0.14$ & $0.93 \pm 0.14$ & $1.20 \pm 0.20$ & $2.47 \pm 1.34$ & $<0.001$ \\
\hline Cardiovascular disease (\%) & 38.3 & 45.2 & 52.6 & 56.1 & $<0.001$ \\
\hline
\end{tabular}

Data are means \pm standard deviation. HDL, high-density lipoprotein; LDL, low-density lipoprotein; eGFR, estimated glomerular filtration rate. $\uparrow$ Body mass index was calculated using weight in kilograms divided by the square of the height in meters. $\$$ Smoking status: daily consumption (pack) $\times$ duration of smoking (year) \{never, light ( $<20$ pack year), moderate (20-39 pack year), heavy ( $\geq 40$ pack year)\}. Data for triglycerides, fasting plasma glucose, and serum bilirubin were skewed and are presented as median (interquartile range) values which were then log-transformed for analysis. *1-way ANOVA test was used for the continuous data and $\chi^{2}$ test for the categorical data.

doi:10.1371/journal.pone.0115294.t001

women aged $81 \pm 8(60-106)$ years. Mean eGFR in the study sample was $56.5 \mathrm{~mL} /$ $\mathrm{min} / 1.73 \mathrm{~m}^{2}$ (SD, 18.8 ), with $1.0 \%$ in stage $1,51.8 \%$ stage $2,21.7 \%$ stage $3 \mathrm{a}$, $14.7 \%$ stage $3 \mathrm{~b}$, and $10.9 \%$ stage 4 . Though age, prevalence of antihypertensive medication, TG, serum uric acid, and serum creatinine level were significantly higher in the lower eGFR group, DBP, HDL-C, and LDL-C were significantly lower. There were no inter-group differences regarding gender, BMI, prevalence of smoking status, SBP, prevalence of antidyslipidemic medication, and FPG.

\section{Estimated GFR of subjects categorized by serum bilirubin level}

Serum bilirubin levels decreased progressively with decreasing eGFR (Table 2), especially for the stage $3 \mathrm{~b}$ or 4 group versus the stages $1+2$ group, and the stage 4 versus the stages $1+2$ to 3 a groups. Moreover, the higher stage 4 group had a higher prevalence of participants with a serum bilirubin of $<0.52 \mathrm{mg} / \mathrm{dL}$.

\section{Relationship of risk factors, including serum bilirubin and eGFR}

Table 3 shows the relationship between participant characteristics and eGFR.

Bilirubin $(r=0.18, P<0.001)$ along with gender, age, BMI, DBP, prevalence of 
Table 2. Serum bilirubin and prevalence of hypobilirubinemia in the subjects by estimated glomerular filtration ratio.

\begin{tabular}{|c|c|c|c|c|c|}
\hline CKD stage $\left(\mathrm{mL} / \mathrm{min} / 1.73 \mathrm{~m}^{2}\right)$ & Stages $1+2$ & Stage $3 a$ & Stage $3 b$ & Stage 4 & \\
\hline eGFR by CKD-EPI equation & $\geq 60.0$ & $59.9-45.0$ & $44.9-30.0$ & $30.0>$ & $P$ for trend* \\
\hline Characteristic $\mathbf{N}=1,050$ & $\mathbf{N}=554$ & $\mathbf{N}=\mathbf{2 2 8}$ & $N=154$ & $N=114$ & \\
\hline Serum bilirubin (mg/dL) & $0.73(0.55-1.00)$ & $0.70(0.52-0.98)$ & $0.64(0.46-0.93)^{a}$ & $0.57(0.42-0.77)^{b, c}$ & $<0.001$ \\
\hline Hypobilirubinemia (\%) & 21.1 & 22.8 & 29.2 & 46.5 & $<0.001$ \\
\hline \multicolumn{6}{|l|}{ (First quartile, $<0.52 \mathrm{mg} / \mathrm{dL}$ ) } \\
\hline
\end{tabular}

Data for serum bilirubin was skewed and presented as median (interquartile range) values, which were then log-transformed for analysis. *1-way ANOVA test was used for the continuous data and $\chi^{2}$ test for the categorical data. ${ }^{a}$ : $P<0.05$; ${ }^{\text {b }: ~} P<0.001$ versus Stages $1+2$. ${ }^{\text {c: }} P<0.001$ versus Stage $3 a$.

doi:10.1371/journal.pone.0115294.t002

antihypertensive medication, TG, HDL-C, and serum uric acid correlated significantly with eGFR (Fig. 1). Stepwise multiple regression analysis using eGFR as an objective variable, and bilirubin, gender, age, prevalence of antihypertensive medication, TG, prevalence of antidiabetic medication, and serum uric acid adjusted for risk factors as explanatory variables, showed that serum bilirubin $(\beta=0.11, P<0.001)$ was significantly and independently associated with eGFR, in addition to gender, age, prevalence of antihypertensive medication, TG, prevalence of antidiabetic medication, and serum uric acid.

Table 3. Relationship between various risk factors including serum bilirubin and estimated glomerular filtration rate.

\begin{tabular}{|c|c|c|c|}
\hline & \multirow[b]{2}{*}{ Pearson's correlation } & \multicolumn{2}{|c|}{ Multiple linear regression } \\
\hline & & Forced method & Stepwise method \\
\hline Characteristic & r (P-value) & $\beta$ (P-value) & $\beta$ (P-value) \\
\hline Gender $($ male $=0$, female $=1)$ & $-0.08(0.007)$ & $-0.10(<0.001)$ & $-0.08(<0.001)$ \\
\hline Age & $-0.36(<0.001)$ & $-0.29(<0.001)$ & $-0.29(<0.001)$ \\
\hline Body mass index & $-0.06(0.039)$ & $-0.04(0.123)$ & 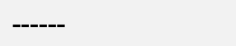 \\
\hline Smoking status & $0.05(0.108)$ & $-0.03(0.272)$ & ----- \\
\hline Systolic blood pressure & $0.05(0.137)$ & ----- & ----- \\
\hline Diastolic blood pressure & $0.17(<0.001)$ & $0.04(0.101)$ & ----- \\
\hline antihypertensive medication & $-0.18(<0.001)$ & $-0.07(0.002)$ & $-0.08(<0.001)$ \\
\hline Triglycerides & $-0.18(<0.001)$ & $-0.06(0.021)$ & $-0.06(0.010)$ \\
\hline HDL cholesterol & $0.10(0.001)$ & $0.00(0.869)$ & ------ \\
\hline LDL cholesterol & $0.05(0.110)$ & $0.03(0.327)$ & ----- \\
\hline Antidyslipidemic medication & $0.00(0.921)$ & $-0.02(0.434)$ & ----- \\
\hline Fasting blood glucose & $-0.04(0.171)$ & $-0.02(0.471)$ & 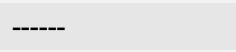 \\
\hline Antidiabetic medication & $-0.06(0.058)$ & $-0.07(0.010)$ & $-0.08(0.001)$ \\
\hline Serum uric acid & $-0.58(<0.001)$ & $-0.52(<0.001)$ & $-0.53(<0.001)$ \\
\hline Serum bilirubin & $0.18(<0.001)$ & $0.11(<0.001)$ & $0.11(<0.001)$ \\
\hline $\mathrm{R}^{2}$ & ----- ～～～～ & $0.47(<0.001)$ & $0.47(<0.001)$ \\
\hline
\end{tabular}

$r$, Pearson's correlation coefficient; $\beta$, standardized coefficient; $R^{2}$, multiple coefficient of determination. Data for triglycerides, fasting plasma glucose, and serum bilirubin were skewed and log-transformed for analysis.

doi:10.1371/journal.pone.0115294.t003 


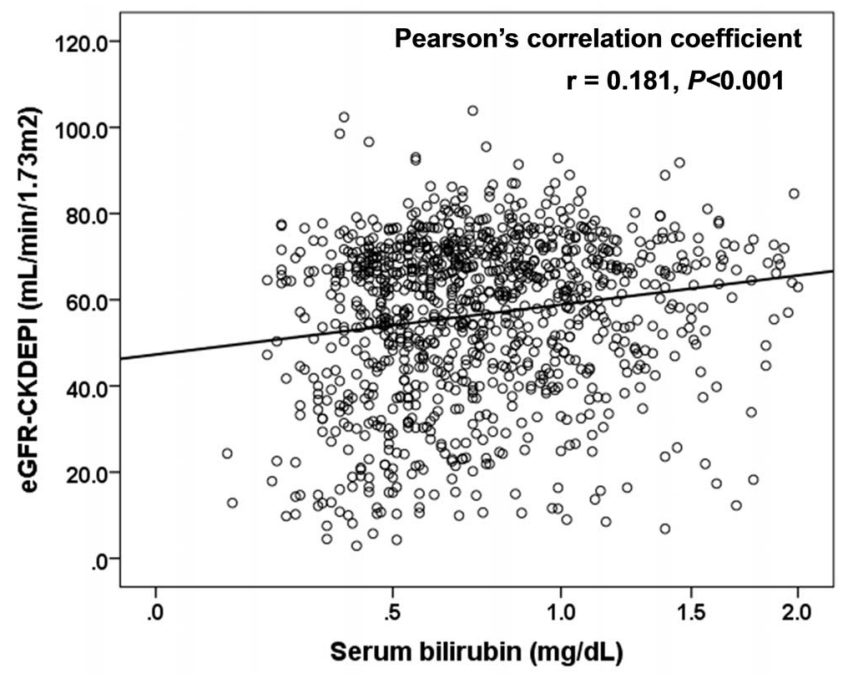

Fig. 1. Relationship between serum bilirubin and estimated glomerular filtration rate (eGFR). eGFR was calculated using CKD-EPI equations modified by a Japanese coefficient (eGFR $141 \times(\mathrm{Cr} / 0.9)^{-0.411} \times 0.993$ age $\times 0.813 ; \mathrm{Cr}>0.9 \mathrm{mg} / \mathrm{dl}, 141 \times(\mathrm{Cr} / 0.9)^{-1.209} \times 0.993$ age $\times 0.813 ;$ Female, $\mathrm{Cr} \leq 0.7 \mathrm{mg} / \mathrm{dl}, 144 \times(\mathrm{Cr} / 0.7)^{-0.329} \times 0.993$ age $\times 0.813 ; \mathrm{Cr}>0.7 \mathrm{mg} / \mathrm{dl}, 144 \times(\mathrm{Cr} / 0.7)^{-1.209} \times 0.993$ age $\times 0.813$. Serum bilirubin was skewed and log-transformed for analysis.

doi:10.1371/journal.pone.0115294.g001

Association between serum bilirubin categories and risk for stage 3 or stage 4 reduced eGFR

Table 4 shows the odds ratio of renal dysfunction for each quartile increase in serum bilirubin and presence of hypobilirubinemia. The non-adjusted, age and gender-adjusted, and multivariate-adjusted odds ratios $\{95 \%$ confidence interval $(\mathrm{CI})\}$ of stage 4 for each quartile in serum bilirubin were $0.62(0.51-0.76), 0.66$ $(0.53-0.80)$, and $0.62(0.46-0.83)$, respectively. Moreover, compared with stages $1+2$, the non-adjusted, age and gender-adjusted, and multivariate-adjusted odds ratios $(95 \% \mathrm{CI})$ of stage 4 for hypobilirubinemia were 3.25 (2.13-4.94), 2.97 $(1.91-4.61)$, and $3.52(1.88-6.59)$, respectively.

\section{Relationship between serum bilirubin and eGFR within selected subgroups}

Next, to control potential confounding factors, the data were further stratified by gender, age, medication (antihypertensive, antidyslipidemic, and antidiabetic agents), and prevalence of CVD (Table 5). The standardized coefficient for eGFR was significant in all of two groups, and there was no interaction between two groups.

\section{Discussion}

To examine any possible contribution of decreased serum bilirubin to decreased renal function among elderly persons, we studied the relationship between risk 
Table 4. Odds ratio of renal dysfunction for decrease in serum bilirubin and hypobilirubinemia.

\begin{tabular}{|c|c|c|c|c|}
\hline \multirow[b]{2}{*}{ CKD stage $\left(\mathrm{mL} / \mathrm{min} / 1.73 \mathrm{~m}^{2}\right)$} & \multicolumn{4}{|c|}{ Odds ratio (95\% confidence interval) } \\
\hline & Stages $1+2$ & Stage $3 a$ & Stage $3 b$ & Stage 4 \\
\hline eGFR by CKD-EPI equation & $\geq 60.0$ & $59.9-45.0$ & $44.9-30.0$ & $<\mathbf{3 0 . 0}$ \\
\hline Characteristic $\mathrm{N}=1,050$ & $\mathbf{N}=\mathbf{5 5 4}$ & $\mathbf{N}=\mathbf{2 2 8}$ & $N=154$ & $\mathbf{N}=114$ \\
\hline Serum bilirubin (per quartile) & 1.00 (referent) & $0.96(0.83-1.11)$ & $0.82(0.69-0.97)$ & $0.62(0.51-0.76)$ \\
\hline Non-adjusted & 1.00 (referent) & $0.98(0.84-1.13)$ & $0.86(0.73-1.03)$ & $0.66(0.53-0.80)$ \\
\hline Gender \& age-adjusted & 1.00 (referent) & $0.96(0.82-1.12)$ & $0.93(0.75-1.15)$ & $0.62(0.46-0.83)$ \\
\hline \multicolumn{5}{|l|}{ Multivariate-adjusted ${ }^{\star}$} \\
\hline Hypobilirubinemia & 1.00 (referent) & $1.10(0.76-1.60)$ & $1.54(1.03-2.31)$ & $3.25(2.13-4.94)$ \\
\hline (First quartile, $<0.52 \mathrm{mg} / \mathrm{dL}$ ) & 1.00 (referent) & $1.07(0.74-1.57)$ & $1.29(0.84-1.98)$ & $2.97(1.91-4.61)$ \\
\hline Non-adjusted & 1.00 (referent) & $1.12(0.75-1.68)$ & $1.03(0.61-1.74)$ & $3.52(1.88-6.59)$ \\
\hline \multicolumn{5}{|l|}{ Age \& gender-adjusted } \\
\hline Multivariate-adjusted* & & & & \\
\hline
\end{tabular}

*Models adjusted for gender, age, body mass index, smoking status, diastolic blood pressure, antihypertensive medication, triglycerides, high density lipoprotein cholesterol, low density lipoprotein cholesterol, antidyslipidemic medication, fasting blood glucose, antidiabetic medication, and uric acid. Data for triglycerides, and fasting plasma glucose were skewed and log-transformed for analysis. Serum bilirubin: quartile-1, 0.21-0.51; quartile-2, 0.52-0.71; quartile-3, 0.72-0.99; quartile-4, $1.00-2.00 \mathrm{mg} / \mathrm{dL}$.

doi:10.1371/journal.pone.0115294.t004

factors including serum bilirubin and eGFR. This study showed a graded decrease in eGFR with decreasing serum bilirubin values starting at $0.52 \mathrm{mg} / \mathrm{dL}$.

Individuals with hypobilirubinemia (first quartile of serum bilirubin, $<0.52 \mathrm{mg} /$ dL) were at a higher risk of stage $4 \mathrm{CKD}$. Surprisingly, multiple linear regression analysis revealed that the strength of serum bilirubin level as an independent determinant of eGFR was similar to those of known factors such as gender, age, prevalence of antihypertensive medication, TG, prevalence of antidiabetic

Table 5. Relationship between serum bilirubin and estimated glomerular filtration rate within selected subgroups.

\begin{tabular}{|c|c|c|c|c|}
\hline Characteristics & $\mathbf{N}$ & $\beta$ (P-value) & P-value & P-interaction \\
\hline \multicolumn{5}{|l|}{ Gender } \\
\hline Men & 413 & 0.11 & 0.008 & 0.778 \\
\hline Women & 637 & 0.10 & 0.001 & \\
\hline \multicolumn{5}{|l|}{ Age } \\
\hline$<80$ years & 415 & 0.13 & 0.002 & 0.605 \\
\hline$\geq 80$ years & 635 & 0.10 & 0.001 & \\
\hline \multicolumn{5}{|l|}{ Medication } \\
\hline Absence & 390 & 0.15 & $<0.001$ & 0.463 \\
\hline Presence & 660 & 0.08 & 0.005 & \\
\hline \multicolumn{5}{|c|}{ Cardiovascular disease } \\
\hline Absence & 590 & 0.07 & 0.034 & 0.080 \\
\hline Presence & 460 & 0.14 & $<0.001$ & \\
\hline
\end{tabular}

$\beta$, standardized coefficient. Medication included antihypertensive, antidyslipidemic, and antidiabetic medications. §Adjusted for all confounding factors in Table 3 by multiple linear regression analysis (Forced method).

doi:10.1371/journal.pone.0115294.t005 
medication, and serum uric acid. To our knowledge, few epidemiologic studies have quantified the link between decreased serum bilirubin and renal function in population-based settings in Japan.

Several studies have shown that decreased serum bilirubin is positively associated with the incidence of CKD. In a community-based cross-sectional study in Korean non-diabetic and diabetic adults (mean age: $55.6 \pm 14.1$ years; 49.1\% male) in Korea, Shin et al [9] found that total serum bilirubin level was negatively correlated with 24-hour urine protein and positively correlated with eGFR after adjustment for potential confounding factors. Fukui et al. [8] found that serum bilirubin was independently and negatively associated with albuminuria in a hospital-based sample of 633 Japanese type 2 diabetic patients (mean age: $64.4 \pm 11.5$ years; $52 \%$ male). In a Japanese cohort study performed on a consecutive series of 2,784 subjects without CKD (58.4\% male) at baseline, serum bilirubin level was suggested as a novel risk factor for the progression of CKD, defined as eGFR $<60 \mathrm{ml} / \mathrm{min} / 1.73 \mathrm{~m}^{2}$ [10]. A longitudinal cohort study of 12,823 Korean male workers aged 30 to 59 years without CKD or proteinuria at baseline reported that higher serum direct bilirubin levels were significantly associated with a lower risk of developing CKD defined as eGFR $<60 \mathrm{ml} / \mathrm{min} /$ $1.73 \mathrm{~m}^{2}$, even following adjustments for important confounders [11]. However, neither serum total nor indirect bilirubin level was significantly associated with incidence of CKD. The findings of Targher et al. [12], however, are in contrast to these. In their observational hospital-based sample of 2,678 US adult outpatients (mean age: $55 \pm 18$ years; $43 \%$ male) they found that serum bilirubin was inversely associated with eGFR in both non-diabetic $(\mathrm{r}=-0.17 ; p<0.0001)$ and diabetic patients $(\mathrm{r}=-0.14 ; p<0.05)$. However, in that study, no adjustment was made for important confounders. In our hospital-based sample of 1,050 elderly persons, we found that multivariate adjusted-odds ratio of hypobilirubinemia for stage 4 (eGFR $<30 \mathrm{ml} / \mathrm{min} / 1.73 \mathrm{~m}^{2}$ ) was $3.52(1.88-6.59)$.

Based on in vitro as well as animal studies, serum bilirubin is generally recognized as an antioxidant substance [15]. In 70 otherwise healthy full-term newborns with neonatal hyperbilirubinemia and 20 control newborns without jaundice, plasma bilirubin showed significant negative correlation with malondialdehyde but positive correlation with antioxidant enzyme activities (such as superoxide dismutase, catalase and glutathione peroxidase levels) [16]. Several studies have demonstrated that serum bilirubin is also negatively associated with CVD $[17,18,19,20]$. We [21] also reported that high serum bilirubin level is negatively associated with carotid atherosclerosis among elderly persons as well as the population of our study. These results demonstrate a protective effect of serum bilirubin on atherosclerosis. Balloon injury-induced neointima formation was less in genetically hyperbilirubinemic Gunn rats and wild-type rats treated with biliverdin, the precursor of bilirubin, than in controls, and both bilirubin and biliverdin inhibited vascular smooth muscle cell proliferation [22]. Moderate hyperbilirubinemia decreases blood pressure in ANG II-dependent hypertension through mechanisms that decrease oxidative stress [23], and improvement of renal hemodynamics may be one mechanism by which moderate hyperbilir- 
ubinemia lowers blood pressure in this model [24]. Moreover, serum unconjugated bilirubin inhibits TNFalpha-related induction of endothelial adhesion molecules and has a protective effect against the development of atherosclerosis [25]. We were unable to assess the antioxidant effect of serum bilirubin, as tests for oxidative stress markers and antioxidant enzymes were not carried out. The results of our study, however, suggest that hypobilirubinemia, which may indicate increased oxidative stress, may be a possible risk factor of CKD independent of other confounding factors.

Some limitations of this study must be considered. First, the cross-sectional study design is limited in the ability to eliminate causal relationships between serum bilirubin and eGFR. Second, estimating GFR tends to be less accurate in subjects with normal renal function and CKD than GFR when inulin clearance is used, but is more accurate than serum creatinine or the Cockcroft-Gault equation [26]. Third, our definition of eGFR is based on a single assessment of serum creatinine, which may introduce a misclassification bias. Fourth, in this study, CKD may have been misclassified with eGFR $>60 \mathrm{ml} / \mathrm{min} / 1.73 \mathrm{~m}^{2}$ and proteinuria as mildly reduced renal function because reduced renal function was defined as reduced eGFR irrespective of the presence or absence of proteinuria. Therefore, the demographics and referral source may limit generalizability.

\section{Conclusions}

In conclusion, the present study showed that decreased serum bilirubin level is strongly associated with decreased eGFR in the elderly. The underlying mechanism behind this relationship is unclear, but seems to be independent of traditional cardiovascular risk factors such as gender, age, hypertension, dyslipidemia, and diabetes. For community-dwelling healthy persons, prospective population-based studies are needed to investigate the mechanisms underlying this association.

\section{Author Contributions}

Conceived and designed the experiments: RK. Performed the experiments: RK T. Kusunoki NO. Analyzed the data: RK T. Kumagi. Contributed reagents/materials/ analysis tools: RK DN YH YK T. Kusunoki NO. Wrote the paper: RK. Critical review of the manuscript: RK DN YK T. Kusunoki T. Kumagi.

\section{References}

1. Levey AS, Andreoli SP, DuBose T, Provenzano R, Collins AJ (2007) Chronic kidney disease: common, harmful and treatable-World Kidney Day 2007. Am J Kidney Dis 49: 175-179.

2. Weiner DE, Tighiouart H, Stark PC, Amin MG, MacLeod B, et al. (2004) Kidney disease as a risk factor for recurrent cardiovascular disease and mortality. Am J Kidney Dis 44: 198-206. 
3. Meisinger C, Doring A, Lowel H, KORA Study Group (2006) Chronic kidney disease and risk of incident myocardial infarction and all-cause and cardiovascular disease mortality in middle-aged men and women from the general population. Eur Heart J 27: 1245-1250.

4. Ishizaka N, Ishizaka Y, Toda E, Koike K, Seki G, et al. (2007) Association between chronic kidney disease and carotid intima-media thickening in individuals with hypertension and impaired glucose metabolism. Hypertens Res 30: 1035-1041.

5. Tiribelli C, Ostrow JD (2005) The molecular basis of bilirubin encephalopathy and toxicity: report of an EASL Single Topic Conference. J Hepatol 43: 156-166.

6. Novotny L, Vitek L (2003) Inverse relationship between serum bilirubin and atherosclerosis in men: a meta-analysis of published studies. Exp Bio Med. (Maywood) 228: 568-571.

7. Ohnaka K, Kono S (2010) Bilirubin, cardiovascular diseases and cancer: epidemiological perspectives. Expert Rev 5: 891-904.

8. Fukui M, Tanaka M, Shiraishi E, Harusato I, Hosoda H, et al. (2008) Relationship between serum bilirubin and albuminuria in patients with type 2 diabetes. Kidney Int 74: 1197-1201.

9. Shin HS, Jung YS, Rim H (2011) Relationship of serum bilirubin concentration to kidney function and 24-hour urine protein in Korean adults. BMC Nephrol 12: 29.

10. Tanaka M, Fukui M, Okada H, Senmaru T, Asano M, et al. (2014) Low serum bilirubin concentration is a predictor of chronic kidney disease. Atherosclerosis 234: 421-425.

11. Ryu S, Chang Y, Zhang Y, Woo HY, Kwon MJ, et al. (2014) Higher serum direct bilirubin levels were associated with a lower risk of incident chronic kidney disease in middle aged Korean men. PLoS One Feb 20; 9: e75178.

12. Targher G, Zoppini G, Cesare Guidi G, Lippi G (2009) Relationship between serum bilirubin and kidney function in non-diabetic and diabetic individuals. Kidney Int 75: 863.

13. Friedewald WT, Levy RI, Fredrickson DS (1972) Estimation of the concentration of low-density lipoprotein cholesterol in plasma, without use of the preparative ultracentrifuge. Clin Chem 18: 499-502.

14. Horio M, Imai E, Yasuda Y, Watanabe T, Matsuo S (2010) Modification of the CKD epidemiology collaboration (CKD-EPI) equation for Japanese: Accuracy and use for population estimates. Am J Kidney Dis 56: 32-38.

15. Stocker R, Yamamoto Y, McDonagh AF, Glazer AN, Ames BN (1987) Bilirubin is an antioxidant of possible physiological importance. Science 235: 1043-1046.

16. Kumar A, Pant P, Basu S, Rao GR, Khanna HD (2007) Oxidative stress in neonatal hyperbilirubinemia. J Trop Pediatr 53: 69-71.

17. Schwertner HA (1998) Association of smoking and low serum bilirubin antioxidant concentrations. Atherosclerosis 136: $383-387$.

18. Schwertner HA, Fischer JR Jr (2000) Comparison of various lipid, lipoprotein, and bilirubin combinations as risk factors for predicting coronary artery disease. Atherosclerosis 150: $381-387$.

19. Djousse L, Levy D, Cupples LA, Evans JC, D’Agostino RB, et al. (2001) Total serum bilirubin and risk of cardiovascular disease in the Framingham offspring study. Am J Cardiol 87: 1196-1200.

20. Kalkan GY, Gür M, Baykan AO, Koyunsever NY, Kaypakli O, et al. (2014) Serum bilirubin level and aortic intima-media thickness in patients without clinical manifestation of atherosclerotic cardiovascular disease. Angiology 65: 308-312.

21. Kawamoto R, Daisuke N, Hasegawa Y, Kasai Y, Kusunoki T, et al. (2014) Mildly elevated serum bilirubin levels are negatively associated with carotid atherosclerosis among elderly persons. PLoS One: in press.

22. Ollinger R, Yamashita K, Bilban M, Erat A, Kogler P, et al. (2007) Bilirubin and biliverdin treatment of atherosclerotic diseases. Cell Cycle 6: 39-43.

23. Stec DE, Storm MV, Pruett BE, Gousset MU (2013) Antihypertensive actions of moderate hyperbilirubinemia: role of superoxide inhibition. Am J Hypertens 26: 918-923.

24. Vera T, Stec DE (2010) Moderate hyperbilirubinemia improves renal hemodynamics in ANG IIdependent hypertension. Am J Physiol Regul Integr Comp Physiol 299: R1044-R1049. 
25. Mazzone GL, Rigato I, Ostrow JD, Bossi F, Bortoluzzi A, et al. (2009) Bilirubin inhibits the TNFalpharelated induction of three endothelial adhesion molecules. Biochem Biophys Res Commun 386: $338-344$.

26. Froissart M, Rossert J, Jacquot C, Paillard M, Houillier $\mathbf{P}$ (2005) Predictive performance of the modification of diet in renal disease and Cockcroft-Gault equations for estimating renal function. J Am Soc Nephrol 16: 763-773. 